\title{
EFFICIENT DECENTRALIZED ENVIRONMENTAL STANDARDS FROM A MODEL OF STRATEGIC INTERJURISDICTIONAL COMPETITION
}

\author{
Mitch Kunce \\ DouglasMitchell Econometric Consulting, Laramie, WY USA
}

\begin{abstract}
The purpose of this paper is to develop a strategic model of interjurisdictional competition where regions choose taxes on two types of capital (locally and absentee owned) and set a level of local environmental quality. Regional strategic interactions are introduced to reinforce the differential returns to and tax treatment of capital types. Moreover, the choice of the level of environmental quality by a jurisdiction is allowed to effect the returns to mobile capital types. The joint determination and fiscal interaction of these three policy variables leads to efficiency in the devolved game. Taxation of mobile capital will not distort the choice of environmental standards when public goods are provided efficiently. Efficiency in public goods provision is enhanced by capital tax exporting.
\end{abstract}

KEYWORDS: environmental federalism, tax competition, tax exporting

JEL CODES: H20, H71, H73

\section{INTRODUCTION}

Formulating the optimal institutional structure in the determination of tax policy and environmental standards remains an important yet unresolved public policy issue. Environmental policy, like taxation, is generated within a system, both in the United States and the European Union that involves several layers of government. Assessing the role of these various governments rises as paramount in task. There is now a large literature that addresses both local public goods and environmental regulation that suggests decentralized decision making is not appropriate and results in suboptimal outcomes in both public goods provision and environmental quality - which are closely intertwined (see Dijkstra and Fredriksson 2010; Wilson 2015 for extensive reviews). The fundamental assertion is that devolved authority will induce local governments to compete for industry and jobs by lowering taxes, reducing environmental regulations, or both. However, a share of this literature forwards well-received exceptions to this reasoning (e.g. Oates and Schwab 1988; Wilson 1996; Wellisch 2000). Derived in firstbest settings, this strand of the literature demonstrates that competition among governments can induce Pareto-efficient local outcomes. Models delivering efficiency

ECRTD-UK https://www.eajournals.org/

ULR:https://doi.org/10.37745/bjes.2013 
follow, generally, two important suppositions - local officials possess a full array of policy instruments to effect Pareto-optimal results and all agents are price takers and do not behave strategically ('competitive' frameworks). This gives rise to a salient question, within a devolved setting can a case be made for efficiency in a model where both suppositions are not followed?

First, an important departure should focus on local governments' access to first-best tax instruments. Fiscal realities and in some situations constraints press the adoption of capital taxation in models which leads to, generally, a misallocation of the capital stock and the underprovision of local public goods (see Wilson and Wildasin 2004). Herein, we will construct a model that taxes only mobile capital. Second, when jurisdictions set fiscal and environmental policy do they simply ignore these same policies being set in other jurisdictions? For example, if a region chooses a high tax rate and stringent emissions standards should they be concerned about the potential loss of tax base to neighboring regions' who may choose more lax policies? A growing empirical literature now lends credibility to the claims that strategic interactions are present in fiscal policy settings and local governments engage in such strategic behavior (see Brueckner 2003; Willardsen 2021 for surveys). Consequently, our model will also feature local governments behaving strategically when choosing capital tax rates and emission standards.

In a recent U.S. tax exporting analysis compiled by Prante and Navin (2016) (PranteNavin), results suggest that up to 45 percent of overall state and local tax collections are ultimately borne by source jurisdiction non-residents. This result is markedly different than the 23 percent found in McLure (1967) and the 26 percent in Morgan et al (1996). The difference is accounted for by what the author's and others coin the "new view" of property tax incidence. Following Zodrow and Mieszkowski (1983), the "new view" treats property taxes as distortionary where distortion effects are reflected in price differentials across local capital markets. As the analysis determines, three key factors affect the ability of jurisdictions to export taxes (i) reliance on property taxation and other taxes on capital, (ii) a jurisdiction may be endowed with an abundance of extractable natural resources, and (iii) tourism draws a wealth of visitors.

Reliance on property taxation at the state and sub-state level in the U.S. is pervasive. Roughly 32 percent of overall state tax revenues are sourced from property taxation making it the largest single source (Prante and Navin 2016). Moreover, 72 percent of local (sub-state) government's tax revenues are sourced from property taxation (UrbanBrookings Tax Policy Center 2017). Regions rich with exploitable natural resources generally tax the production post severing it from the ground (Kunce and Morgan 2005). The incidence of these 'severance' taxes generally falls on the producing firms as assumed by Prante-Navin. In most cases, extraction firms are owned outside the region where

ECRTD-UK https://www.eajournals.org/ ULR:https://doi.org/10.37745/bjes.2013 
production occurs. Lastly, jurisdictions' with a large tourism sector can exploit nonresident taxation very efficiently. Sales, specific use, transportation and lodging taxes generally dominate fiscal structures in these regions.

Prante-Navin found that 27 states and the District of Columbia ${ }^{1}$ are net tax exporters in the calendar year 2012. A net tax exporter is defined by taking gross tax revenues exported (per capita) less gross tax revenues imported (per capita) for a specific state. ${ }^{2}$ The top five largest net tax exporting jurisdictions (per capita) are Alaska, North Dakota, District of Columbia, Tennessee and Hawai'i. Interestingly, Alaska's net tax exporting proficiency exceeds that of North Dakota's by a factor 2 to 1 . Prante-Navin do not address excess burden costs or local public goods spillovers in their extensive examination.

Paired with the recent Prante-Navin findings, contributions from the new economic geography (NEG) literature have elevated the importance of understanding mobile capital tax exporting and its welfare effects. ${ }^{3}$ Previously, mobile factor tax exporting was viewed as scarcely important and received scant attention in the literature. The purpose of this paper is to develop a strategic model of interjurisdictional competition where regions choose taxes on two types of capital (locally and absentee owned) and set a level of local environmental quality. Regional strategic interactions are introduced to reinforce the differential returns to and tax treatment of capital types. Moreover, the choice of the level of environmental quality by a jurisdiction is allowed to effect the returns to mobile capital types. Herein, the joint determination and fiscal interaction of these three policy variables leads to efficiency in the devolved game. The optimal provision of local public goods that leads to an efficient level of environmental quality is found to be a CournotNash equilibrium in this decentralized setting.

\section{THE MODEL}

Suppose for simplicity that an area's economy consists of two symmetric regions (indexed by $i=1,2$.) where the jurisdictions are large enough that pollution generated in one region does not spill-over to the other. ${ }^{4}$ The region's population is fixed and each identical resident owns an equal share of a productive fixed factor $L_{i}$. Each region

\footnotetext{
${ }^{1}$ Commuting from surrounding states (along with tourism) bolsters the District's ability to tax export.

${ }^{2}$ See Prante and Navin (2016) Table 4. p. 46-47.

${ }^{3}$ See Baldwin and Krugman (2004) for a review of contributions from the (NEG) literature. Essentially, agglomeration forces may mitigate tax competition pressures through capital tax exporting. However, reconciling NEG with traditional tax competition appears tenuous (Fernandez 2005).

${ }^{4}$ The presumption of symmetric regions allows us to avoid the potential inefficiencies in which Tiebouttype regions are inefficiently organized or incongruously stratified by class, information, wealth or size. Moreover, if inefficiencies arise in a symmetric setting, they are likely to be exacerbated in an asymmetric construct.
}

ECRTD-UK https://www.eajournals.org/ ULR:https://doi.org/10.37745/bjes.2013 
produces a homogeneous numeraire private good that is sold in a national market. Production requires capital inputs, $K_{i}$ and $C_{i}$, the regional fixed factor, $L_{i}$, and pollution emissions, $E_{i}$, which is treated as a non-purchased input akin to Oates and Schwab (1988). The fixed domestic-capital stock, $\bar{K}$, is owned in equal regional shares, $\eta_{i}$, by residents. ${ }^{5}$ The fixed capital stock, $\bar{C}$, is owned entirely by agents outside the two regions modeled. ${ }^{6}$ Absentee-capital owners are committed to invest the entirety of $\bar{C}$ to the modeled economy. Attractive risk rewards, favorable tax deduction reciprocities, preferential treatment, general agglomeration forces and/or strong complementarities to other regional production inputs surface as decisive factors for this investment.

In this devolved setting, local authorities set a standard for environmental quality holding other regions' choices as given. For example, jurisdictions may specify an allowable level of the concentration of pollutants. Herein, this level is captured by, $E$, where this standard effects both local technology and regional welfare. Let $f(K, C, L, E)$ denote each jurisdiction's constant-returns-to-scale technology. Production possesses all conventional curvature properties hence all marginal products $f_{K}, f_{C}, f_{L}, f_{E}$ are positive and diminish $f_{K K}$, $f_{C C}, f_{L L}, f_{E E}<0$, where subscripts denote partial derivatives. Concavity requires,

$$
\begin{aligned}
& {[\cap]=f_{K K} f_{C C}-f_{C K} f_{K C}>0,} \\
& 2 f_{K L} f_{C L} f_{K C}-\left(f_{K L}\right)^{2} f_{C C}-\left(f_{C L}\right)^{2} f_{K K}+[\cap] f_{L L}<0,
\end{aligned}
$$

where each successive leading principal minor (Hessian) determinate alternates signs. Linear homogeniety of production and Euler's theorem establishes,

$$
f(K, C, L, E)=f_{K} K+f_{C} C+f_{L} L+f_{E} E,
$$

while differentiating equation (3) with respect to each input yields,

$$
\begin{aligned}
& f_{K K} K+f_{C K} C+f_{L K} L+f_{E K} E=0, \\
& f_{K C} K+f_{C C} C+f_{L C} L+f_{E C} E=0,
\end{aligned}
$$

\footnotetext{
${ }^{5}$ Following convention, the model focuses on the allocation of a fixed stock rather than new capital formation. Additionally, from this point forward the use of subscripts will be limited, however functions are understood to be region specific.

${ }^{6}$ See Wildasin (1989) for a similar construct, though the implications of tax exporting are not explored. In a two region model, Mongrain and Wilson (2018) treat 'foreign capital (firms)' as the other region's domestic mobile capital.
}

ECRTD-UK https://www.eajournals.org/

ULR:https://doi.org/10.37745/bjes.2013 


$$
\begin{aligned}
& f_{K L} K+f_{C L} C+f_{L L} L+f_{E L} E=0, \\
& f_{K E} K+f_{C E} C+f_{L E} L+f_{E E} E=0 .
\end{aligned}
$$

Additionally, Young's theorem allows us to define all common mixed partial derivatives as equal, for example $f_{C K}=f_{K C}$. Equations (4) - (7) constrain at least one mixed partial in each equation to be positive.

Both capital types are perfectly mobile within and across regions (at least in the long run) following,

$$
K_{1}+K_{2}=\bar{K} \text { and } C_{1}+C_{2}=\bar{C} .
$$

Regions in this strategic construct possess some level of market power over returns to mobile factors. Let $r$ and $\rho$ denote endogenous net returns to domestic and absenteeowned capital. Each capital type faces separate source based unit taxation. Capital types contribute to a region's technology distinctively warranting differential tax treatment that enhances a jurisdiction's welfare (Smith 1999, Kunce 2000). ${ }^{7}$ Profit maximizing mobile factor equilibrium conditions become,

$$
r=f_{K}-t \text { and } \rho=f_{C}-\tau
$$

denoting that the net return of capital inputs are equal to the after tax value of each marginal product. Since both types of capital are mobile, respective net returns must be equalized across regions. Equations (8) and (9) provide the necessary system of equations required to determine equilibrium values of $K, C, r$ and $\rho$ as implicit functions of tax rates $t, \tau$ and pollution emissions $E$. The following is a summary of the relevant jurisdiction specific comparisons derived. The ratio of two differentials are interpreted as partial derivatives when holding all other variables constant.

$$
\begin{aligned}
& \frac{\mathrm{d} K}{\mathrm{~d} t}=\frac{f_{C C}}{2[\cap]}<0, \frac{\mathrm{d} K}{\mathrm{~d} \tau}=\frac{-f_{K C}}{2[\cap]}, \frac{\mathrm{d} K}{\mathrm{~d} E}=\frac{f_{K C} f_{C E}-f_{K E} f_{C C}}{2[\cap]}, \\
& \frac{\mathrm{d} C}{\mathrm{~d} t}=\frac{-f_{K C}}{2[\cap]}, \frac{\mathrm{d} C}{\mathrm{~d} \tau}=\frac{f_{K K}}{2[\cap]}<0, \frac{\mathrm{d} C}{\mathrm{~d} E}=\frac{f_{K C} f_{K E}-f_{K K} f_{C E}}{2[\cap]},
\end{aligned}
$$

\footnotetext{
${ }^{7}$ Parallels are lifted from the commodity tax literature, see Mintz and Tulkens (1986). In a related vein, Mongrain and Wilson (2018) model a preferential tax system where foreign and domestic capital face different tax rates.

ECRTD-UK https://www.eajournals.org/ ULR:https://doi.org/10.37745/bjes.2013
} 


$$
\begin{aligned}
& \frac{\mathrm{d} r}{\mathrm{~d} t}=-\frac{1}{2}<0, \frac{\mathrm{d} r}{\mathrm{~d} \tau}=0, \frac{\mathrm{d} r}{\mathrm{~d} E}=\frac{f_{K E}}{2} \\
& \frac{\mathrm{d} \rho}{\mathrm{d} t}=0, \frac{\mathrm{d} \rho}{\mathrm{d} \tau}=-\frac{1}{2}<0, \frac{\mathrm{d} \rho}{\mathrm{d} E}=\frac{f_{C E}}{2}
\end{aligned}
$$

Irrefutable signs stemming from the maximization hypothesis apply to six of the comparisons shown in equations (10) - (13), signs of the other six are ambiguous and depend on production input relationships that we will explore in more detail below.

Output from production is consumed as a composite private good, $X$, or supplied to the regional government to produce a Samuelsonian public good, G. The public good is financed by taxing both types of capital where,

$$
G=t K+\tau C
$$

Regional consumption is defined,

$$
X=f(K, C, L, E)-r K-\rho C-G+r \eta \bar{K}
$$

which represents output net of returns to capital types, public good financing and adding back the region's domestic capital ownership returns. Fixed, identical residents of a region receive utility from consumption and local public goods, but suffer disutility from the level of pollution emissions. Regional utility takes the form, $U(X, G, E)$, where $U_{X}$ and $U_{G}>0$, but $U_{E}<0$. Higher $E$ corresponds to poorer environmental quality where $E$ represents a pure public bad. In keeping with the Arrow-Debreu (Wilson 1999) separation assumption for general equilibrium constructs, residents have two distinct roles in the model. First, as consumers, they seek to maximize utility over a bundle of goods and services. Second, supplying production inputs and in return receiving income returns. More of the mobile factors and lax environmental standards enhance local production and can provide residents with higher incomes hence more consumption. However, in order to attract the mobile factors, the jurisdiction lowers taxes (effecting $G$ ) and/or relaxes environmental regulations (lowering utility directly) thus setting up a characteristic economic tradeoff.

Will imperfect competition among jurisdictions lead to efficiency? Since all residents in the model are fixed and identical, we can reduce the analysis to a regional focus providing a useful benchmark. Social efficiency requires the maximization of a region's utility subject to (i) utility in all other jurisdictions is equalized to a fixed level, (ii) aggregate production and consumption clear, and (iii) the mobile factor stocks are

ECRTD-UK https://www.eajournals.org/

ULR:https://doi.org/10.37745/bjes.2013 
allocated entirely among regions (clear). The resulting social optimum conditions are well known (see Oates 1988; Wilson 1996) therefore derivation discussion in this section is keep to a minimum. Ignoring any corner solutions, efficiency becomes,

$$
\begin{aligned}
& \operatorname{MRS}_{G, X}=\frac{U_{G}}{U_{X}}=1 \quad \forall i, \\
& -M R S_{E, X}=\frac{-U_{E}}{U_{X}}=f_{E} \quad \forall i, \\
& f_{K}^{i}=f_{K}^{j} \text { and } f_{C}^{i}=f_{C}^{j} \quad \forall i, j \quad j \neq i .
\end{aligned}
$$

Equation (16) represents the familiar 'Samuelson condition' for the provision of public goods (Wilson 1996). This appropriate optimality condition suggests that the marginal rate of substitution $\left(M R S_{G, X}\right)$ between the public good and consumption (over all regional residents) equals the marginal cost of providing an incremental increase in the public good. Given equations (14) and (15), the marginal rate of transformation in this context is one for one. Equation (17) shows that regions should choose a combination of environmental quality and consumption such that the marginal rate of substitution between the two equals the marginal product of emissions (recall that $U_{E}<0$ ). Equation (17) represents a Samuelson rule for environmental quality, if you will. Equation (18) shows the optimal clearing condition for the mobile production factors.

Regional governments play a Cournot-Nash game in tax rates and pollution standards. Acting as benevolent dictators, authorities in each region will choose $t, \tau$ and $E$ that maximize the common utility of its residents, subject to holding these policies in the other region as given. A region's utility maximizing conditions, in total differential form, become,

$$
\mathrm{d} U=U_{X} \mathrm{~d} X+U_{G} \mathrm{~d} G+U_{E} \mathrm{~d} E=0
$$

where,

$$
\mathrm{d} X=f_{K} \mathrm{~d} K+f_{C} \mathrm{~d} C+f_{L} \mathrm{~d} L+f_{E} \mathrm{~d} E-(r \mathrm{~d} K+K \mathrm{~d} r)-(\rho \mathrm{d} C+C \mathrm{~d} \rho)-\mathrm{d} G+\eta \bar{K} \mathrm{~d} r,
$$

and,

$$
\mathrm{d} G=t \mathrm{~d} K+K \mathrm{~d} t+\tau \mathrm{d} C+C \mathrm{~d} \tau
$$

ECRTD-UK https://www.eajournals.org/ ULR:https://doi.org/10.37745/bjes.2013 
Recall that $L$ is fixed in the jurisdiction's point of view. Best response (reaction) functions are derived by evaluating equations (19) - (21) with respect to each choice variable where,

$$
(t): U_{X} \frac{\mathrm{d} X}{\mathrm{~d} t}+U_{G} \frac{\mathrm{d} G}{\mathrm{~d} t}+U_{E} \frac{\mathrm{d} E}{\mathrm{~d} t}=0,
$$

and,

$$
\begin{aligned}
& \frac{\mathrm{d} X}{\mathrm{~d} t}=f_{K} \frac{\mathrm{d} K}{\mathrm{~d} t}+f_{C} \frac{\mathrm{d} C}{\mathrm{~d} t}-\left(r \frac{\mathrm{d} K}{\mathrm{~d} t}+K \frac{\mathrm{d} r}{\mathrm{~d} t}\right)-\left(\rho \frac{\mathrm{d} C}{\mathrm{~d} t}+C \frac{\mathrm{d} \rho}{\mathrm{d} t}\right)-\frac{\mathrm{d} G}{\mathrm{~d} t}+\eta \bar{K} \frac{\mathrm{d} r}{\mathrm{~d} t}, \\
& \frac{\mathrm{d} G}{\mathrm{~d} t}=t \frac{\mathrm{d} K}{\mathrm{~d} t}+K+\tau \frac{\mathrm{d} C}{\mathrm{~d} t}, \text { with } \frac{\mathrm{d} E}{\mathrm{~d} t}=0 .
\end{aligned}
$$

Evaluating equations (22) and (23) at the symmetric equilibrium where $\eta=1 / 2$ resulting in $\eta \bar{K}=K$ and using equations (9) yields,

$$
(t):\left[\frac{U_{G}}{U_{X}}-1\right]\left[t \frac{\mathrm{d} K}{\mathrm{~d} t}+K+\tau \frac{\mathrm{d} C}{\mathrm{~d} t}\right]+t \frac{\mathrm{d} K}{\mathrm{~d} t}+\tau \frac{\mathrm{d} C}{\mathrm{~d} t}-C \frac{\mathrm{d} \rho}{\mathrm{d} t}=0 .
$$

To complete the best response function with respect to $t$, we substitute into equation (24) the relevant comparisons from equations (10) - (13) resulting in,

$$
(t):\left[\frac{U_{G}}{U_{X}}-1\right]\left[t\left(\frac{f_{C C}}{2[\cap]}\right)+K-\tau\left(\frac{f_{K C}}{2[\cap]}\right)\right]+t\left(\frac{f_{C C}}{2[\cap]}\right)-\tau\left(\frac{f_{K C}}{2[\cap]}\right)=0 .
$$

Following the same derivation procedure, best response functions for $\tau$ and $E$ become,

$$
(\tau):\left[\frac{U_{G}}{U_{X}}-1\right]\left[-t\left(\frac{f_{K C}}{2[\cap]}\right)+C+\tau\left(\frac{f_{K K}}{2[\cap]}\right)\right]-t\left(\frac{f_{K C}}{2[\cap]}\right)+\tau\left(\frac{f_{K K}}{2[\cap]}\right)+\frac{C}{2}=0,
$$

ECRTD-UK https://www.eajournals.org/ ULR:https://doi.org/10.37745/bjes.2013 


$$
\begin{aligned}
(E): & \frac{U_{E}}{U_{X}}+f_{E}+\left[\frac{U_{G}}{U_{X}}-1\right]\left[t \frac{f_{K C} f_{C E}-f_{K E} f_{C C}}{2[\cap]}+\tau \frac{f_{K C} f_{K E}-f_{K K} f_{C E}}{2[\cap]}\right]+t \frac{f_{K C} f_{C E}-f_{K E} f_{C C}}{2[\cap]} \\
& +\tau \frac{f_{K C} f_{K E}-f_{K K} f_{C E}}{2[\cap]}-C \frac{f_{C E}}{2}=0
\end{aligned}
$$

Solving equations (25) - (27) simultaneously yields the optimal tax rules with efficiency in public goods provision,

$$
t=-C f_{K C} \text { and } \tau=-C f_{C C} \text {, }
$$

where the optimal level of $E$ follows,

$$
\frac{-U_{E}}{U_{X}}=f_{E} .
$$

From equations (28) a mix of capital taxation is chosen in light of the efficient provision of regional public goods. An interior utility maximizing condition in public goods requires,

$$
G=C\left(-K f_{K C}-C f_{C C}\right)>0,
$$

or when using equation (5),

$$
G=C\left(L f_{C L}+E f_{C E}\right)>0 .
$$

An unambiguous efficient interior public goods result is secured when absentee-capital productivity is enhanced by the region's fixed factor $\left(f_{C L}>0\right)$ and allowed emissions $\left(f_{C E}\right.$ $>0$ ). This requisite is intuitively appealing given the necessary absentee-capital investment assumptions discussed above.

\section{ANALYSIS OF THE COURNOT-NASH RESULT}

The optimal tax rule for domestically owned capital is dependent on the region's production relationship between the two capital types, $f_{K C}$. For example, if the marginal product of domestic-capital diminishes with incremental increases in absentee-capital employed (substitutes), $t$ is positive. Conversely, a complementary relationship gives rise to domestic-capital subsidies. No relationship between capital types would yield, $t=0$.

ECRTD-UK https://www.eajournals.org/

ULR:https://doi.org/10.37745/bjes.2013 
The maximization hypothesis, concavity, production linear homogeneity and interior solution conditions generate no firm boundaries regarding the sign of $f_{K C}$. Nevertheless, a substitute relationship between capital types would bolster concavity bounds imposed by equation (2) and interior solution restrictions shown in equation (30).

Alternatively, a region's optimal absentee owned capital tax rate is unambiguously positive. Devolved efficiency is the consequence of shifting taxes to non-resident capital owners. Because the welfare of non-residents secures no weight in a region's objective function, tax exporting becomes welfare enhancing. Alternatively, tax exporting counteracts the tension created by mobile factor tax competition and allows for the efficient provision of the local Samuelsonian public good. Conversely, tax structures that restrict taxation to domestically owned mobile factors would not yield such efficient outcomes (Smith 1999; Wilson 2015). A note of interpretive caution, the feasibility of this Nash equilibrium collapses once absentee-capital commitments erode. Strong, longrun synergism between absentee-capital and a region is crucial to this optimal decentralized result.

Equation (29) shows that a region will choose a level of $E$ that is socially optimal. The best response function shown in equation (27) reveals the connection in the determination of environmental quality and local public goods. In equilibrium, the efficient provision of $G$, through tax exporting, triggers disincentives to chase capital types with lax environmental standards. Therefore, maximizing behavior implies that a region will set $E$ so that the change in regional consumption equals the marginal willingness to pay for environmental quality. Since the change in regional consumption equals the change in output with respect to a marginal change in $E$, the marginal willingness to pay for environmental quality equals the marginal product of the environment.

\section{CONCLUDING REMARKS}

Convention, in the setting of interjurisdictional economic competition, envisions a raceto-the-bottom when decentralized jurisdictions, in their eagerness to attract commerce, introduce policies to reduce business costs in the form of tax structures that underprovide public goods and lax pollution standards that lower environmental quality. The current body of empirical evidence, however, does not provide compelling support for the race within the context of environmental federalism (Dijkstra and Fredriksson 2010). The theoretical work herein debits the inventory of literature questioning the race-to-thebottom claim. Somewhat analogous to the NEG literature findings where mobile factors tied to a geographical location through agglomeration forces can be taxed and not produce a race-to-the-bottom outcome. The linchpin securing this NEG result, through economic integration, relies on the mobile factor becoming "quasi-fixed" to a location (Baldwin and Krugman 2004; Fernandez 2005).

ECRTD-UK https://www.eajournals.org/

ULR:https://doi.org/10.37745/bjes.2013 
As shown herein, taxation of mobile capital will not distort the choice of environmental standards when public goods are provided efficiently. In effect, efficiency in public goods provision is enhanced by capital tax exporting. When examining property tax incidence using the "new view", capital tax exporting can no longer be perceived as scarcely important and may provide a mechanism for welfare enhancing interjurisdictional competition in a second-best setting. As an aside - by examining a number of factors effecting a state's environmental quality, McKinsey \& Company compiles an annual ranking of U.S. states for overall environmental quality. For the year 2012, Hawai'i and North Dakota were ranked first and second in environmental quality while ranking fifth and second in net tax exporting (see above). In closing, I recall the foundational query forwarded by Wallace Oates - devolved environmental management, welfare enhancing or distortion inducing?

\section{REFERENCES}

Baldwin, R. and Krugman, P. (2004) Agglomeration, integration and tax harmonization. European Economic Review 5: 1-23.

Brueckner, J. (2003) Strategic interaction among governments: an overview of empirical studies. International Regional Science Review 26(2): 175-188.

Dijkstra, B. and Fredriksson, P. (2010) Regulatory environmental federalism. Annual Review of Resource Economics 2: 319-339.

Fernandez, G. (2005) A note on tax competition in the presence of agglomeration economies. Regional Science and Urban Economics 35: 837-847.

Kunce, M. (2000) A Nash tax game extending the generality of the Henry George Theorem. Economics Letters 66: 229-233.

Kunce, M. and Morgan, W. (2005) Taxation of oil and gas in the U.S. 1970-1997. Natural Resources Journal 45(1): 77-101.

McKinsey \& Company (2012) Best states ranking of environmental quality. U.S. News and World Report. https://www.mckinsey.com.

McLure, C. (1967) The interstate exporting of state and local taxes: Estimates from 1962. National Tax Journal 20(3): 49-77.

Mintz, J. and Tulkens, H. (1986) Commodity tax competition between member states of a federation: Equilibrium and efficiency. Journal of Public Economics 29: 133-172.

Mongrain, S. and Wilson, J. (2018) Tax competition with heterogeneous capital mobility. Journal of Public Economics 167: 177-189.

Morgan, W., Mutti, J. and Rickman, D. (1996) Tax exporting, regional economic growth, and welfare. Journal of Urban Economics 39: 131-159.

Oates, W. and Schwab, R. (1988) Economic competition among jurisdictions: Efficeincy enhancing or distortion inducing. Journal of Public Economics 35: 333-354.

ECRTD-UK https://www.eajournals.org/

ULR:https://doi.org/10.37745/bjes.2013 
Prante, G. and Navin, J. (2016) Estimating state and local tax exporting between 1999 and 2012. Journal of Applied Business and Economics 18(4): 36-53.

Smith, S. (1999) Tax competition with two types of capital. Journal of Urban Economics 45: 177-183.

Wellisch, D. (2000) Theory of Public Finance in a Federal State. Cambridge University Press.

Wildasin, D. (1989) Nash equilibria in models of fiscal competition. Journal of Public Economics 35: 229-240.

Willardsen, K. (2021) Measuring fiscal interactions in local federalism. Papers in Regional Science 100(4): 891-923.

Wilson, J. (1996) Capital mobility and environmental standards: Is there a theoretical basis for a race to the bottom? in Fair Trade and Harmonization, Vol. 1, eds. J. Bhagwati and R. Hudec. MIT Press, pp. 395-427.

Wilson, J. (1999) Theories of tax competition. National Tax Journal 52: 269-304.

Wilson, J. (2015) Tax competition in a federal setting, in Handbook of Multilevel Finance, eds. E. Ahmad and G. Brosio. Edward Elgar Publishing, pp. 264-290.

Wilson, J. and Wildasin, D. (2004) Capital tax competition: bane or boon. Journal of Public Economics 88: 1065-1091.

Urban-Brookings Tax Policy Center. (2017) State and local finance initiative data query system. http://www.taxpolicycenter.org.

Zodrow, G. and Miezkowski, P. (1983) The incidence of the property tax: The benefit view versus the new view, in Local Provision of Public Services: The Tiebout Model after Twenty-five years, Ed. G. Zodrow. New York: Academic Press, pp. 109-129.

ECRTD-UK https://www.eajournals.org/ 